\title{
REVIEW
}

\section{Excitatory Amino Acids and Alzheimer's Disease}

\author{
J. TIMOTHY GREENAMYRE AND ANNE B. YOUNG ${ }^{1}$ \\ Department of Neurology, University of Michigan \\ Neuroscience Laboratory Building, 1103 East Huron, Ann Arbor, MI 48104-1687
}

Received 14 April 1989

\begin{abstract}
GREENAMYRE, J. T. AND A. B. YOUNG. Excitatory amino acids and Alzheimer's disease. NEUROBIOL AGING 10(5) 593-602, 1989. - Excitatory amino acids (EAA) such as glutamate and aspartate are major transmitters of the cerebral cortex and hippocampus and EAA mechanisms appear to play a role in learning and memory. Anatomical and biochemical evidence suggests that there is both pre- and postsynaptic distuption of EAA pathways in Alzheimer's disease. Dysfunction of EAA pathways could play a role in the clinical manifestations of Alzheimer's disease, such as memory loss and signs of cortical disconnection. Furthermore, EAA might be involved in the pathogenesis of Alzheimer's disease, by virtue of their neurotoxic (excitotoxic) properties. Circumstantial evidence raises the possibility that the EAA system may partially determine the distribution of pathology in Alzheimer's disease and may be important in producing the neurofibrillary tangles, RNA reductions and dendritic changes which characterize this devastating disorder. In this article, we will review the evidence suggesting a role for EAA in the clinical manifestations and pathogenesis of Alzheimer's disease.
\end{abstract}

Alzheimer's disease Excitatory amino acids Excitotoxin Glutamate Kainate NMDA Quisqualate Receptor

ALZHEIMER'S disease is the most common dementing illness in the Western world; it affects about one in six persons over the age of $65(60)$. Alzheimer's disease has traditionally been viewed as a "cortical" dementia (143). It is marked by memory loss, personality changes and signs of cortical disconnection such as apraxia, aphasia and agnosia. In keeping with this clinical impression of cortical dysfunction, substantial pathology in Alzheimer's disease falls on the cortical structures (89). The hallmarks of Alzheimer's disease are neurofibrillary tangles and amyloid-containing neuritic plaques in cerebral cortex and hippocampus (60). In addition, the large pyramidal neurons in the neocortex and in the CAl region of hippocampus are significantly depleted $(71,137)$.

More recently, substantial subcortical pathology has been noted. In the nucleus basalis of Meynert and other areas of the basal forebrain, a considerable loss of cholinergic neurons is usually observed (106). Similarly, serotonergic neurons in the median raphe (70) and noradrenergic neurons in the locus ceruleus (11) are variably depleted, especially in early onset cases. Emphasis has been placed upon the loss of cholinergic innervation to the cerebral cortex and it has been suggested that the dementia of Alzheimer's disease is primarily due to this deficit (26). However, several lines of evidence argue against this notion. First, a subset of demented Alzheimer's patients with typical neuropathological findings have normal levels of choline acetyl transferase (CAT) in the cerebral cortex (96). Second, some demented Alzheimer's patients have normal numbers of cholinergic neurons in the nucleus basalis of Meynert $(101,103)$. Finally, in another neurodegenerative disorder, olivopontocerebellar atrophy, basal forebrain neurons are lost and there is a concomitant reduction of cortical CAT activity of the same magnitude as that seen in moderate to severe, clinically disabling Alzheimer's disease (61). However, these patients are not demented, "and scored within or close to the normal range on a simple mental status screening examination." It should be noted that detailed neuropsychological testing revealed "generally mild" deficits in these patients. The authors concluded that "cholinergic reduction may explain only part of the pathophysiology of the dementia of [Alzheimer's disease]." Thus it is unclear whether pathology in one neurotransmitter system is primarily responsible for the clinical signs and symptoms of Alzheimer's disease. Also a matter of controversy is whether the primary lesion in Alzheimer's disease is cortical or subcortical (3).

Examination of the major cortical and hippocampal neurotransmitter systems is of importance because of the profound cortical and hippocampal pathology in Alzheimer's disease. Excitatory amino acids, such as glutamate and aspartate, are thought to be the

\footnotetext{
'Requests for reprints should be addressed to Anne B. Young, M.D., Ph.D., Department of Neurology, University of Michigan, Neuroscience Laboratory Building, 1103 E. Huron, Ann Arbor, MI 48104.
} 
principal excitatory neurotransmitters of cortical and hippocampal neurons $(36,39,44)$. In this article, we will review the evidence that excitatory amino acids are affected in Alzheimer's disease, that they may play a role in the pathogenesis of Alzheimer's disease and that dysfunction of the excitatory amino acid system may be responsible for some of the clinical manifestations of this disease.

\section{EXCITATORY AMINO ACIDS AS NEUROTRANSMITTERS}

Glutamate, aspartate, homocysteic acid and cysteine sulfinic acid are all putative endogenous excitatory amino acid neurotransmitters. Of these, glutamate is the best characterized and is likely to serve as the major excitatory neurotransmitter of the central nervous system $(36,39,44)$. This dicarboxylic, acidic amino acid is the most abundant amino acid in the brain (39). Glutamate is intimately involved in intermediary metabolism and it can be synthesized via a number of different pathways. The rate limiting step for the synthesis of the neurotransmitter pool of glutamate, if there is one, is unknown (39). Neurotransmitter glutamate is apparently actively taken up and stored in synaptic vesicles (88) and, upon depolarization, glutamate is released in a calciumdependent fashion (105). Glutamate released into the synaptic cleft is rapidly inactivated by a sodium-dependent high-affinity uptake system which is present in both neurons and glia (39).

Under appropriate experimental conditions, the molecular processes mediating calcium-dependent release and high-affinity uptake can be measured to map putative EAA pathways. Most homogenate and tissue slice autoradiographic methods appear to measure selectively the presynaptic neuronal uptake site (39). Because these processes are localized to nerve terminals, EAA uptake or release will be reduced in the terminal fields (projection sites) of lesioned EAA pathways. More recently, immunocytochemical methods have been employed to directly visualize conjugated glutamate in neurons and glia (134). This technique appears to label the neurotransmitter pool of glutamate, although this is a subject of controversy (95) and different antibodies may yield differing results. By combining lesion studies with measures of uptake and release, immunocytochemistry and electrophysiology, a wide variety of putative EAA pathways have been identified (38). These include corticocortical pathways, corticofugal pathways (including fibers to striatum, thalamus, brainstem and spinal cord), hippocampal afferents, intrinsic neurons and efferents, cerebellar afferent fibers and intrinsic cells, primary sensory afferents and spinal cord intrinsic neurons.

\section{EAA Receptors}

The excitatory actions of EAA are mediated through at least four different receptor types $(90,125,142)$. Under the most common receptor classification scheme, N-methyl-D-aspartate (NMDA), quisqualate and kainate receptors have been named for the agonist which is most specific at that receptor type. There is also a "metabotropic" receptor which is coupled to inositol phosphate metabolism $(90,125)$. Virtually all cells in the central nervous system are depolarized by EAA, suggesting the presence of receptors on most neurons. Some EAA, such as glutamate, are "nonselective agonists," meaning that they can interact with each of the receptor types. Quisqualate receptors appear to mediate fast excitatory neurotransmission (29). Although somewhat controversial, NMDA receptors also appear to function in normal synaptic transmission $(22,138)$. The function of kainate receptors is unclear.

The NMDA receptor is the best characterized of the three receptor types. Glutamate, aspartate, homocysteate and quinoli- nate are endogenous EAA that can activate the NMDA receptor, whereas NMDA itself is a synthetic analog which specifically activates this receptor $(41,78)$. The NMDA recognition site (binding site) is coupled to an ion channel, which is gated by magnesium in a voltage-dependent manner $(79,93)$. Thus, when the cell is in its normal polarized state. the ion channels are blocked by magnesium and the NMDA receptor is difficult to activate. However, when, for any given reason, the neuron becomes relatively depolarized, the magnesium blockade is lifted. Dissociative anesthetics, such as phencyclidine (PCP), ketamine and the recently developed drug MK-801, bind to and block this ion channel, and thereby act as noncompetitive antagonists of the NMDA receptor system $(59,67,138)$. Anatomical and biochemical studies indicate that the PCP receptor is associated with the NMDA receptor ion channel complex (74) and, currently, the term "PCP receptor" is considered synonymous with the NMDA receptor ion channel (109). The NMDA receptor complex also has a glycine recognition site, activation of which appears to be necessary for NMDA receptor function $(58,62)$. Thus, the NMDA receptor is a large macromolecular complex with various recognition and regulatory sites. In contrast to our current understanding of the NMDA receptor, the structure and function of quisqualate and kainate receptors are just beginning to be elucidated.

Recently, receptor binding assays have been developed to label selectively the NMDA $(45,83,85)$, quisqualate $(17,52,86,91)$ and kainate receptor $(10,51,81,121,140)$ recognition sites, as well as the PCP receptor $(74,124,141,149)$ and the NMDA receptor-associated glycine site $(15,23,68,112,130)$. Quantitative receptor autoradiography has been used to determine the pharmacological characteristics and precise regional localization of these receptor types. The regional distributions of NMDA recognition sites, PCP receptors and glycine recognition sites are highly correlated $(23,74)$. The density of NMDA receptors is higher in the forebrain than in brain stem, cerebellum or spinal cord, and is especially high in stratum moleculare of dentate gyrus, stratum radiatum of $\mathrm{CA} \perp$ and outer layers of cerebral cortex; receptor density is intermediate in the basal ganglia and thalamus. Quisqualate receptors are most prevalent in the molecular layer of cerebellum, outer layers of cerebral cortex, stratum moleculare of the dentate gyrus, stratum radiatum of the hippocampus and striatum. Moderate numbers of quisqualate receptors are found in thalamus and hypothalamus. Kainate receptors are the most dense in the stratum lucidum of the hippocampus. Moderate levels of kainate receptors are found in the deep layers of cerebral cortex, the striatum and granular layer of cerebellum; there is less binding in outer layers of cerebral cortex, thalamus and cerebellar molecular layer. Thus, EAA receptors are distributed widely throughout the brain, especially in cortex and hippocampus.

\section{EAA in Learning, Memory and Plasticity}

In addition to their function as excitatory neurotransmitters, EAA appear to play important roles in learning and memory, developmental synaptic plasticity, neuronal survival and dendritic outgrowth and regression. In the hippocampus, NMDA antagonists can block certain aspects of the development of long-term potentiation (LTP), a model of memory formation $(19,20,50)$. These agents also impair spatial discrimination learning in rats (87). In some cases, normal synaptic plasticity is dependent upon NMDA receptor activation. For example, the plasticity of binocular connections in the visual cortex of the kitten can be disrupted by a one hour exposure to the NMDA antagonist, aminophosphonopentanoic acid (110). Similarly, normal activity-dependent developmental plasticity of the visual system can be disrupted by NMDA antagonists (63). 
It has also been suggested that activation of the NMDA receptor may exert a trophic influence during development. During differentiation, activation of the NMDA receptor promoted the survival of cultured cerebellar granule cells (6). This effect was stage-dependent and blocked by a competitive NMDA antagonist. Furthermore, at higher, subtoxic doses, EAA can cause regression and simplification of the dendritic arbor of hippocampal pyramidal cells in vitro $(75,76)$. EAA, therefore, have biphasic effects, promoting growth and differentiation at low concentrations and inhibiting them at higher concentrations.

\section{EAA as Neurotoxins}

A unique property of EAA neurotransmitters is their neurotoxicity $(94,114,115)$. The ability of EAA to cause neuronal depolarization correlates with their ability to produce axon-sparing neurotoxic lesions and has led to the concept of "excitotoxins" (94). Both the excitatory and toxic effects of EAA can be blocked by receptor antagonists, suggesting that both phenomena are mediated by receptors. Excitotoxicity can occur by activation of NMDA, quisqualate or kainate receptors. The mechanism of neurotoxicity appears to involve 2 processes (115). First, depolarization can result in passive chloride influx, which causes subsequent cation and water entry and may lead to osmotic lysis. Second, depolarization through NMDA receptors also causes calcium influx (18), which leads to delayed neuronal damage due to mitochondrial dysfunction and protease and lipase activation. Other factors may also contribute to excitotoxicity. For example, under hypoxic/ischemic conditions, high affinity glutamate uptake is depressed such that glutamate may exert more prolonged effects upon its receptors $(120)$. In addition, when neurons are unable to maintain their normal membrane potential, the voltage-dependent magnesium gating of the NMDA receptor ion channel is lifted and the neurons are more susceptible to NMDA receptor-mediated damage (92). Neurotoxicity is therefore enhanced by any process that disrupts cellular energy metabolism.

Because of their ubiquitous distribution and neurotoxic potential, it has been proposed that EAA may be involved in the pathogenesis of both acute and chronic neurodegenerative diseases $(36,44,94,115)$. For example, several lines of evidence suggest that excitotoxicity is involved in hypoxic/ischemic brain damage (114). Hypoxia/ischemia causes a simultaneous large increase in glutamate release (9) and a marked depression of high-affinity glutamate uptake (120). Removal of EAA innervation to a given region protects against subsequent hypoxic/ischemic damage (144). Global hypoxia/ischemia produces preferential damage of superficial cortical layers, the $\mathrm{CAl}$ region of hippocampus, striatum and cerebellar Purkinje cells, regions with high densities of EAA receptors $(14,45,85)$. Most importantly, in models of global and focal hypoxia/ischemia, EAA antagonists exert a profound protective effect $(40,115,122)$. Similarly, there is evidence suggesting a role for EAA in the pathogenesis in Huntington's disease $(8,27,69,147)$, epilepsy (126), hypoglycemic brain damage (145), lathyrism (132) and amyotrophic lateral sclerosis (133).

\section{EXCITATORY AMINO ACID MARKERS IN ALZHEIMER'S DISEASE}

\section{EAA Levels}

The simplest but least specific marker of EAA function is measurement of EAA levels. Glutamate and aspartate are intimately involved in intermediary metabolism in the central nervous system, and the neurotransmitter pool of these amino acids is only a small fraction of the total. However, in regions with dense glutamatergic innervation, the neurotransmitter pool of glutamate and aspartate may be as high as $30 \%-40 \%$ of the total (39). Several studies have examined excitatory amino acid concentrations in Alzheimer's and control brains. Some of these studies have shown significant decreases in glutamate levels in cortex and hippocampus of Alzheimer's patients $(4,35,116)$, but other studies have shown no changes $(102,104)$. A somewhat different approach was taken by Hyman et al. (53). These workers had previously shown that the cells of origin of the perforant pathway to the hippocampus are destroyed in Alzheimer's disease (54). Because this pathway is believed to be glutamatergic, they microdissected a portion of the pathway's terminal zone and found an $83 \%$ decrease in the level of free glutamate in Alzheimer's disease patients (53). More recently, Bowen and colleagues have examined amino acid levels in biopsy samples from very early Alzheimer's disease and control brains (108). They reported a significant decrease in glutamate levels in the temporal cortex and a significant increase in aspartic acid in the temporal and frontal cortex of Alzheimer's disease patients. In later stages of the disease, samples of brain obtained within three hours of death were also analyzed for amino acids, and a much larger decrease in glutamate was found in the Alzheimer's cases. Amino acids have also been examined in the cerebrospinal fluid of Alzheimer's disease patients and controls (127). Although there were no overall differences in aspartic or glutamic acid in the Alzheimer's disease patients, there was a significant correlation between cerebrospinal fluid levels of glutamate and cognitive test scores.

In summary, measurements of excitatory amino acid levels have yielded conflicting results. However, when these measurements were made in regions of dense glutamatergic innervation, in biopsy samples or in postmortem samples obtained within three hours of death, there did appear to be significant decreases in glutamate levels in Alzheimer's patients.

\section{EAA Uptake and Release}

More specific biochemical markers for EAA neurons include sodium-dependent high-affinity uptake and calcium-dependent release $(39,44)$. High-affinity sodium-dependent uptake was measured in a synaptosomal preparation of previously frozen brains from Alzheimer's disease and control subjects (49). Under these conditions there was a $60 \%$ decrease of uptake sites in cortical and hippocampal regions. However, studies in rat brain have indicated that freezing results in a $50 \%-80 \%$ decrease in uptake activity compared to fresh tissue, and prolonged freezing results in a further decrement of uptake $(49,117)$.

More recently, some laboratories have examined sodiumdependent D-aspartate binding because it was thought that this would be a more stable marker of the uptake site $(24,28,123)$. Unfortunately, in homogenates (30) and, more recently, in autoradiographic assays $(13,48)$, sodium-dependent D-aspartate binding has been found to have properties inconsistent with neuronal, presynaptic uptake sites. In homogenates (30), thorough washing of membranes in distilled water abolishes subsequent sodiumdependent D-aspartate binding. This, and several other inconsistencies have led the authors to conclude that D-aspartate binding "does not represent binding to the transport carrier." In an autoradiographic assay (48), sodium dependent D-aspartate binding has a regional distribution unlike that expected for a presynaptic neuronal uptake site. Furthermore, lesions of EAA pathways do not result in decreased binding (uptake) in the terminal fields of those pathways, contrary to what would be expected for a marker of the neuronal uptake site $(13,48)$.

In fresh unfrozen tissue, Bowen and colleagues (108) have demonstrated a $40 \%-50 \%$ decrease in D-aspartate synaptosomal uptake in Alzheimer's disease brain. EAA release from biopsy samples of temporal cortex from patients with Alzheimer's disease 
was reportedly normal (128); however, the calcium dependence of release was not examined. More recently, the same authors have reported that calcium-dependent release could not be demonstrated in fresh tissue obtained from prompt postmortem tissue samples (108).

\section{EAA Immunocytochemistry}

Another direct measure of EAA neurons is by means of EAA immunocytochemistry (134). The interpretation of glutamate and aspartate immunocytochemistry is somewhat controversial and may depend, in part, on the particular antibody used. It is also unclear whether antibodies to these compounds are labeling a metabolic or neurotransmitter pool (95). Despite these uncertainties, it appears that in many regions glutamate and aspartate immunocytochemistry label populations of putative EAA neurons. This technique has been applied to the study of Alzheimer's disease brains and it has been shown by two different laboratories that glutamate immunoreactivity is localized in cortical and hippocampal pyramidal neurons, many of which contain neurofibrillary tangles $(64,73)$. In the future, it may be possible to use immunocytochemistry to perform quantitative morphometric studies of EAA neurons in Alzheimer's disease brains.

\section{EAA Receptors}

In addition to these presynaptic measures of EAA neurons, there is also evidence of postsynaptic EAA dysfunction in Alzheimer's disease. Greenamyre et al. (47) described a loss of glutamate binding sites in the neocortex of Alzheimer's patients when compared to normal controls and patients with Huntington's disease. When subtypes of EAA receptors were examined, it appeared that NMDA receptors were affected more than quisqualate receptors. A similar, profound loss of NMDA receptors was found in the hippocampus of Alzheimer's disease patients (46). Represa et al. (111) also reported large losses of NMDA receptors in Alzheimer's hippocampus. In contrast, Geddes et al . (43) and Cowburn et al. $(24,25)$ found no significant NMDA receptor changes in neocortex or hippocampus.

Maragos et al. (72) described a loss of PCP receptors (NMDA receptor ion channels) in $\mathrm{CA} 1, \mathrm{CA} 3$ and subiculum of the hippocampus of Alzheimer's disease patients. A $40 \%$ loss of PCP receptors in CA1 was reported by Cotman and colleagues (82). Interestingly, although Cotman and colleagues reported an average $40 \%$ loss of PCP receptors in CA1 and no significant loss of NMDA sites, they found a correlation coefficient of 0.92 between the 2 sites in the same brains (82). Simpson et al. (123) examined PCP receptor binding in homogenates of Alzheimer's brains and they found no significant changes in PCP receptors in hippocampus, temporal cortex or caudate nucleus, but they did observe a $35 \%$ decrease in frontal cortex.

Geddes et al. (43) described an expanded distribution of kainate binding sites in the molecular layer of the dentate gyrus in Alzheimer's disease hippocampi, but the density of binding sites was unchanged. In contrast, Represa et al. (111) reported a significant loss of kainate sites in dentate gyrus and no expansion of the distribution of these sites.

There may be several reasons for the discrepancies in the results of NMDA and PCP receptor binding in Alzheimer's disease reported by different laboratories. First, differences in assay conditions and buffers may produce different results. Second, receptor binding in homogenate preparations may mask significant changes in discrete anatomical laminae. Third, severity of disease might determine the degree of receptor changes measured. Further studies will be necessary to clarify these issues. The studies to date, however, suggest that the degree of NMDA and PCP receptor loss is related to the severity of Alzheimer's pathology $(42,72,82,111)$. However, the loss of the NMDA/PCP receptor complex is not a simple reflection of neuronal loss as discussed below. Furthermore, given the discrete distribution of NMDA receptor losses in hippocampus, it is likely that homogenate studies $(24,25,123)$ would not detect these changes.

In summary, measurement of EAA markers including endogenous EAA levels, synaptosomal uptake and immunocytochemistry provides compelling evidence for loss of EAA-utilizing neurons in Alzheimer's disease. Because these EAA neurons themselves receive extensive EAA input, it would be expected that degeneration of these cells (pyramidal cells of the neocortex and CAI region of hippocampus) would result in a loss of EAA receptors. In fact, autoradiographic studies have generally shown a loss of NMDA receptors in certain hippocampal subfields in Alzheimer's disease $(46,72,82,111)$. Of critical importance, but still unanswered, is the question of when during the course of the disease these changes in EAA transmission occur. The clinical implications of this pre- and postsynaptic disruption of EAA neurotransmission are discussed in a subsequent section.

\section{THE RELATIONSHIP OF EAA TO PATHOLOGY IN ALZHEIMER'S} DISEASE

\section{Neurofibrillary Tangles}

A characteristic neuropathological finding in Alzheimer's disease is the presence of neurofibrillary tangles in the perikarya of many neurons in the cortex, hippocampus and basal forebrain $(60,136)$. The neurofibrillary tangles are composed of accumulations of paired helical filaments (136). Interesting observations have been reported relating EAA to neurofibrillary tangles. One study (which has not been replicated) suggested that incubation of cultured human neurons with aspartate or glutamate induced the formation of paired helical filaments similar to those which make up neurofibrillary tangles (32). Antibodies against the abnormal cytoskeletal elements found in Alzheimer's disease have not been used to determine whether the epitopes on the paired helical filaments seen in this culture experiment are in fact similar to those on the paired helical filaments in Alzheimer's disease. On the other hand, immunocytochemical data do suggest that the antigenic composition of neurofibrillary tangles observed in the amyotrophic lateral sclerosis-parkinsonism-dementia of Guam is similar to that of tangles observed in Alzheimer's disease (118). This observation suggests that there is a common pathogenetic mechanism for neurofibrillary tangle formation in these diseases. Because the pathogenesis of amyotrophic lateral sclerosis-parkinsonism-dementia of Guam has been tentatively linked to an excitotoxin acting at the NMDA receptor (133), a similar excitotoxic mechanism may play a role in the formation of neurofibrillary tangles in Alzheimer's disease. The mechanism by which EAA induce paired helical filaments is unknown. One might speculate that EAA, by opening calcium channels, or by activation of the inositol phospholipid cascade, could activate protein kinases and cause abnormal phosphorylation of neurofilament or tau proteins. Such a possibility has been proposed as a mechanism for neurofibrillary degeneration (57).

\section{RNA Reductions}

In a study of 17 patients with Alzheimer's disease verified histologically, cognitive test scores correlated highly with pathological changes in large cortical pyramidal (EAA) neurons, as assessed by cell loss, reductions in nuclear and nucleolar volumes and cytoplasmic RNA content (89). A disorder in RNA synthesis has been demonstrated repeatedly in Alzheimer's disease $(12,65$, 89 ). In both human and mouse neurons, glutamate, in subtoxic 
doses can reduce RNA content $(32,34)$. The alteration in RNA metabolism may simply indicate that damaged neurons process RNA differently. Alternatively, reductions in neuronal nucleolar volumes and cytoplasmic RNA content (89) may be markers for excitotoxic damage.

\section{Distribution of Plaques and Tangles}

Careful, systematic examination of the distribution of neurofibrillary tangles and senile (neuritic) plaques suggests that these lesions do not occur randomly, but may have an anatomical basis. Regions of cortex that are interconnected by cortical association pathways are much more severely affected than are primary motor, somatosensory, visual or auditory cortex $(37,99)$. The laminar distribution of plaques in the affected regions correlates extremely well with those regions involved in corticocortical association systems (113). It has been suggested on a purely anatomical basis that the disease process may progress along these putative EAA connecting pathways (99). Although these studies provide strong evidence that the characteristic pathology of Alzheimer's disease distributes in relation to EAA cortical association pathways, the mechanism by which plaques and neurofibrillary tangles organize along these pathways is unknown. EAA receptor-mediated mechanisms may play a role in this distribution and contribute to the degeneration of neurons which are already compromised. However, receptor distribution alone cannot explain the regional localization of neuron loss, plaques and neurofibrillary tangles, as discussed below.

\section{Dendritic Changes}

During the course of Alzheimer's disease, there is a loss of normal dendritic elements and a progressive simplification of the dendritic arbor of cortical neurons $(71,80)$. Subtoxic doses of glutamate induce identical regression of dendrites in cultured hippocampus neurons $(75,76)$. The affected dendrites are found primarily on pyramidal projection cells which normally receive extensive synaptic input from other cortical EAA neurons. A loss of the dendritic arbor would be expected to impair communication between regions of cortex.

In some cases, in addition to the loss of normal dendrites and dendritic spines, there is a proliferation of abnormal, bizarre dendritic structures $(56,107)$. In these instances, aberrant filopodia are often present $(56,107)$. Similar filopodia-like structures are seen transiently after focal application of glutamate in cultured neurons [(129) and Mattson M.P., personal communication]. Thus, in cultured neurons, EAA can reproduce some of the dendritic changes seen in Alzheimer's disease. The relevance to the changes in Alzheimer's disease of this potential for EAA to modify dendritic structure is not yet known.

\section{EAA and the Pathogenesis of Alzheimer's Disease}

Do EAA play a role in the pathogenesis of Alzheimer's disease? The current evidence is tantalizing but only circumstantial. Similar to Alzheimer's disease, EAA can reduce neuronal RNA content, may induce the formation of paired helical filaments, and can cause regression of the pyramidal cell dendritic arbor. Furthermore, the distribution of pathology in Alzheimer's disease appears to be intimately related to EAA corticocortical association pathways.

What role, if any do EAA receptors play in the pathogenesis of this disorder? The loss of EAA receptors in the cortex and hippocampus in Alzheimer's disease might be interpreted as being consistent with a loss of structures containing EAA receptors via an excitotoxic mechanism. Alternatively, the loss of EAA recep- tors could simply be due to shrinkage of the dendritic arbor of cortical and hippocampal pyramidal neurons, or could reflect neuronal loss, as suggested by Cotman and colleagues (42). NMDA receptor losses do appear to be related to the severity of pathology but this is not a simple relationship since the distribution of NMDA receptor losses and the regional pattern of pathological changes in Alzheimer's disease are poorly correlated, as discussed below.

Because the distribution of pathology in Alzheimer's disease appears to occur in relation to EAA association pathways (37. 99. 113 ), and because postsynaptic NMDA receptors mediate excitotoxic events, it could be argued that the distribution of NMDA receptors should be a major determinant of the regional localization of pathological changes. Alternatively, the presence of NMDA receptors could be necessary but not sufficient to cause these changes; other factors such as density of EAA afferents, or intrinsic properties of the neurons such as their relative efficiency in sodium-calcium exchange, might then determine relative vulnerability.

Based on a comparison of NMDA receptors in normal brains and pathological changes in Alzheimer's disease, it does not appear that NMDA receptor localization is the major determinant of the distribution of pathology. In normal human hippocampal formation, NMDA receptor binding is highest in CAl, with less binding in the stratum moleculare of the dentate gyrus; CA3 and subiculum both have considerably lesser densities of binding than the CAl region; entorhinal cortex appears to have even less binding than subiculum $(42,46,72,111)$. This rank order of NMDA receptor density in human hippocampus is similar to that seen in rat brain $(45,83,85)$. In contrast, neuronal loss is most severe, and neurofibrillary tangles and senile plaques are most concentrated in entorhinal cortex, subiculum and $\mathrm{CA} 1$ region $(54,55)$, while dentate gyrus and CA3 are relatively spared. Thus, more severe pathology can affect regions with fewer NMDA receptors, and areas rich in NMDA receptors may show little pathological involvement. The distribution of NMDA receptors in various regions of neocortex has not been studied in detail and the relationship between NMDA receptors and neocortical pathology is largely unknown.

It is apparent from the studies to date that NMDA receptor distribution is not the major factor determining the regional pattern of pathological changes in Alzheimer's disease. It is also clear that NMDA receptor loss is not a simple reflection of cell loss because receptors are relatively spared in some regions where there is substantial cell loss (i.e., temporal cortex and subiculum) and are decreased in areas where there is little neuronal depletion (i.e., CA3).

If excitotoxic mechanisms are still to be invoked in the pathogenesis of the degenerative changes of Alzheimer's disease, what can account for the distribution of these changes? Is it useful to consider the excitotoxic hypothesis of hypoxic/ischemic hippocampal damage. Hypoxia/ischemia causes a large increase in extracellular glutamate levels by both increasing glutamate release (9) and impairing severely the high affinity uptake system which normally inactivates EAA (120). This results in elevated glutamate levels in the synaptic cleft and prolonged activation of EAA receptors. The pattern of neuronal damage in the hippocampus after hypoxic/ischemic insults is almost identical to that in Alzheimer's disease: CA 1 neurons are severely damaged and CA 3 and dentate gyrus neurons are relatively unaffected (14). This pattern cannot be simply related to NMDA receptor distribution. yet NMDA receptor antagonists confer a profound protection from hypoxic/ischemic damage $(114,115)$. This indicates that activation of NMDA receptors is involved in the pathogenesis of hypoxic/ ischemic damage, but NMDA receptor distribution alone does not determine the regional pattern of excitotoxic damage. 
Recent work by Mattson and Kater (77) suggests that EAA receptors may play a necessary permissive role in excitotoxicity, but intrinsic properties of neurons from different regions may determine their relative vulnerability to excitotoxic damage. Neurons from subfields of the hippocampus were cultured separately and then exposed to toxic concentrations of glutamate. Pyramidal cells from the CA1 region were selectively vulnerable, whereas pyramidal neurons from $\mathrm{CA} 3$ and granule cells from the dentate gyrus were relatively resistant. This pattern of selective vulnerability is similar to that observed in hypoxia/ischemia and in Alzheimer's disease. Although these excitotoxic effects were mediated by NMDA receptors, it appears that there is some intrinsic property (or properties) of the neuron, related to its site of origin within the hippocampus, that determines its susceptibility to excitotoxins. Different neuronal populations may vary in their relative ability to handle increased intracellular calcium loads, in the efficiency of their intracellular calcium buffering system and in their capabilities for sodium-calcium exchange. Such differences may play a role in their selective vulnerability to neurotoxic damage.

These findings may help explain the anatomical correlation between Alzheimer's disease pathology and cortical association pathways. EAA innervation and release via cortical association pathways, together with postsynaptic NMDA receptors, may provide a necessary but insufficient substrate for pathological excitotoxic damage. As yet undetermined intrinsic properties of regionally distinct groups of neurons may determine their relative vulnerability, and thus, the distribution of pathology.

It is important to note that EAA could contribute to the distribution and severity of neuronal damage in Alzheimer's disease, even if an aberration of EAA systems were not the primary defect in this disorder. For example, when the energy stores of neurons are impaired, they are less able to maintain their normal membrane potential. This reduces the voltage-dependent magnesium blockade of the NMDA-associated ion channel and results in increased susceptibility to NMDA neurotoxicity (92). In this way, EAA may be a secondary cause of neuronal damage in Alzheimer's disease, and neurons which are compromised by some other pathological process may be rendered more vulnerable to EAA.

THE RELATIONSHIP OF EAA CHANGES TO CLINICAL MANIFESTATIONS OF ALZHEIMER'S DISEASE

Patients with Alzheimer's disease become progressively forgetful and develop profound abnormalities of cognition and orientation; signs of "cortical disconnection," such as apraxias, aphasias, and agnosias are also common. A defect in EAA neurotransmission may contribute to this clinical picture. EAA appear to be crucial in learning and memory $(19,87)$. Activation of NMDA receptors is required for the development of long-term potentiation (a model of memory formation) in the CAl region and dentate gyrus of hippocampus in vitro. Competitive and noncompetitive NMDA antagonists prevent the development of long-term potentiation, and perfusion of a competitive NMDA antagonist impairs spatial learning in vivo $(19,87)$. The important role of EAA in learning and memory, together with evidence that cortical and basal forebrain cholinergic deficits alone are not sufficient to cause dementia (61), suggests that pre- and postsynaptic disruption of EAA transmission may contribute to the learning and memory deficits of Alzheimer's disease. The clinical signs of cortical disconnection may also result from disruption of glutamatergic pathways. Large pyramidal cortical neurons which give rise to association pathways are putatively glutamatergic $(21,23)$ and pathological changes in these neurons are correlated with decline in mental test performance (89). The distribution of senile plaques and neurofibrillary tangles correlates closely with these EAA pathways. There is evidence, based on EAA levels, uptake and immunocytochemistry, that presynaptic EAA neurons are damaged in Alzheimer's disease. Furthermore, the loss of cortical and hippocampal EAA receptors and ion channels in Alzheimer's disease is likely to further impair communication between various regions of cortex. Thus, disruption of EAA neurotransmission could potentially play a very important role in the clinical signs and symptoms of Alzheimer's disease patients.

\section{THERAPEUTIC MODULATION OF EAA IN ALZHEIMER'S DISEASE}

In recent years, the principal target of therapy for Alzheimer's disease has been the muscarinic cholinergic system. However, evidence suggests that the cholinergic system is not invariably affected in demented Alzheimer's disease patients. Further, severe deficits of cortical and basal forebrain cholinergic activity are not necessarily associated with dementia (61). Therapeutic trials with muscarinic agonists and acetylcholinesterase inhibitors have been largely unsuccessful (7). The one possible exception to this failure of cholinergic therapy has been a preliminary trial with tetrahydro9-aminoacridine (THA) (135). THA is a potent acetylcholinesterase inhibitor with an $\mathrm{IC}_{50}$ of $0.1-0.2 \mu \mathrm{M}(98)$. At concentrations above $1.0 \mu \mathrm{M}$, THA also acts as a muscarinic (M1 and M2) antagonist (98). Thus, if THA were present in brain concentrations in the low micromolar range, the blockade of muscarinic receptors would be expected to offset the anticholinesterase effects of THA. At slightly higher concentrations, THA interacts with the NMDA ion channel/PCP receptor site (2). It has recently been found in mice that a single dose of THA which produces a therapeutic plasma level, results in a ten-fold concentration of THA in the brain, with peak THA concentrations of $2.4 \mu \mathrm{M}(66)$. Conceivably, on a regular dosing schedule, steady-state concentrations of THA in brain could be even higher than after the single dose used in this study. At this reported concentration, THA could be expected to have significant cholinergic antagonist effects, and would also act at the NMDA ion channel. This raises the possibility that the effects of THA on the muscarinic system may be less important than previously thought, and the interaction with the PCP receptor may be clinically relevant.

There is indirect clinical evidence that THA may be an antagonist of PCP receptors. It reverses magnesium chlorideinduced coma (119) and decreases the duration of anesthesia produced by the dissociative anesthetics, phencyclidine and ketamine (1). Furthermore, THA potentiates quinolinate's NMDA receptor-mediated toxicity (148), presumably by its interaction with the PCP site (2). In this way, THA may actually augment EAA neurotransmission at the NMDA receptor site.

Because disruption of EAA neurotransmission could possibly produce some of the clinical manifestations of Alzheimer's disease, treatment with EAA agonists might theoretically be of some benefit. It has even been suggested that "clinical trials examining the therapeutic efficacy of glutamate in this disorder are warranted" (33). While augmentation of the EAA system in Alzheimer's disease may seem attractive, it is probably not feasible and is potentially quite dangerous. Under normal circumstances, the acidic amino acid transport system by which glutamate is translocated across the blood-brain barrier is saturated with ambient plasma concentrations of EAA (97). Furthermore, the concentration of glutamate in brain is approximately 5-10 mM. Thus, it seems unlikely that manipulation of plasma concentrations of EAA would significantly alter brain levels of these compounds, unless extremely high doses were used (139). In Alzheimer's disease, there may be a disruption of the blood-brain barrier (146) and glutamate might enter the brain more freely. Because of a loss of neuronal glutamate uptake sites (108), higher levels of glutamate 
would more likely be toxic. In this regard, it is relevant that chronic administration of an excitotoxin with a lower potency than glutamate, in doses of $0.7-2.0 \mathrm{mmol} / \mathrm{kg} / \mathrm{day}$, causes extensive damage to cortical pyramidal cells in primates (133).

If EAA-induced neurotoxicity plays either a primary or secondary role in the pathogenesis of Alzheimer's disease, it might be expected that EAA antagonists would retard the progression of this disorder. The involvement of EAA in learning and memory, however, means that direct EAA antagonism would likely further impair Alzheimer's patients.

Given our current understanding of EAA pharmacology, it is unlikely that EAA agonist or antagonist therapy will be of benefit. However, EAA pharmacology is complex and there are multiple sites at which potential therapeutic agents might be directed. For example, the glycine recognition site on the NMDA receptor complex must be occupied by an "agonist" (glycine-like) compound in order for the NMDA receptor to be functional (62). Modulation of this site with agonist, antagonist or mixed agonistantagonist drugs may produce clinically beneficial results with minimal side effects. In a similar fashion, drugs which modify PCP receptor function may be useful. In addition, it may be possible to exploit EAA agonists as "cognition enhancing" drugs, by combining their use with agents that block specifically the postreceptor mechanisms responsible for toxicity. There may also be different agonist- and antagonist-preferring states of the NMDA receptor (84), selective modulation of which may be of clinical utility.

\section{SUMMARY}

Excitatory amino acids, particularly glutamate and aspartate, are the major excitatory neurotransmitters of the cerebral cortex and hippocampus. Pre- and postsynaptic defects in EAA neurotransmission may account, in part, for the clinical manifestations of Alzheimer's disease. The excitotoxic properties of EAA might contribute to the pathogenesis of this disorder. Further study of EAA in Alzheimer's disease may lead to a better understanding of the cause of this devastating illness and might lead to new therapeutic strategies.

\section{ACKNOWLEDGEMENTS}

Supported by USPHS grant AG 06155 and the Arbogast Foundation.

\section{REFERENCES}

1. Albin, M. S.; Bunegin, L.; Massopust, L. C.; Janetta, P. J. Ketamine-induced post-anesthetic delerium attenuated by tetrahydroaminoacridine. Exp. Neurol. 44:126-129; 1974.

2. Albin, R. L.; Young, A. B.; Penney, J. B. Tetrahydro-9-aminoacridine (THA) interacts with the phencyclidine (PCP) receptor site. Neurosci. Lett. 88:303-307; 1988.

3. Appel, S. H. A unifying hypothesis for the cause of amyotrophic lateral sclerosis, parkinsonism, and Alzheimer's disease. Ann. Neurol. 19:499-505; 1981.

4. Arai, H.; Kobayashi, K.; Ichimiya, Y.; Kosaka, K.; lizuk, R. Free amino acids in post-mortem cerebral cortices from patients with Alzheimer-type dementia. Neurosci. Res. 2:486-490; 1985.

5. Arendt, T.; Zvegintseva, H. G.; Leontovich, T. A. Dendritic changes in the basal nucleus of Meynert and in the diagonal band nucleus in Alzheimer's disease - A quantitative Golgi investigation. Neuroscience 19:1265-1278; 1986.

6. Balazs, R.; Hack, N.; Jorgensen, O. S. Stimulation of the Nmethyl-D-aspartate receptor has a trophic effect on differentiating cerebellar granule cells. Neurosci. Lett. 87:80-86; 1988.

7. Bartus, R. T.; Dean, R. L., III; Beer, B.; Lippa, A. S. The cholinergic hypothesis of geriatric memory dysfunction. Science 217:408-427: 1982

8. Beal, M. F.; Kowall, N. W.; Ellison, D. W.; Mazurek, M. F.; Swartz, K. J.; Martin, J. B. Replication of the neurochemical characteristics of Huntington's disease by quinolinic acid. Nature 321:168-172; 1986.

9. Beneviste, H.; Drejer, J.; Schousboe, A.; Diemer, N. H. Elevation of extracellular concentrations of glutamate and aspartate in rat hippocampus during transient cerebral ischaemia monitored by intracerebral micro-dialysis. J. Neurochem. 43:1369-1374; 1982.

10. Berger, $M$.; Ben-Ari, Y. Autoradiographic visualization of ${ }^{3} \mathrm{H}-k$ ainic acid receptor subtypes in the rat hippocampus. Neurosci. Lett. 39:237-242; 1983.

11. Bondareff, W.; Mountjoy, C. Q.; Roth, M. Loss of neurons of origin of the adrenergic projection to cerebral cortex (nucleus locus ceruleus) in senile dementia. Neurology 32:164-168; 1982.

12. Bowen, D. M.; Smith, C. B.; White, P.; Davison, A. N. Neurotransmitter-related enzymes and indices of hypoxia in senile dementia and other abiotrophies. Brain 99:459-496; 1976.

13. Bridges, R. J.; Anderson, K. J.; Tavoularis, A. L.; Bhatt, D.; Cotman, C. W. Lesion induced changes in glutamate uptake sites. Soc. Neurosci. Abstr. 14:421; 1988.

14. Brierly, J. B.; Graham, D. I. Hypoxia and vascular disorders of the central nervous system. In: Adams, J. H.; Corsellis, J. A. N.; Duchen, L. W., eds. Greenfield's neuropathology. New York: John Wiley \& Sons Inc.; 1984:125-207.
15. Bristow, D. R.; Bowery, N. G.; Woodruff, G. N. Light microscopic autoradiographic localization of $\left[{ }^{3} \mathrm{H}\right]$ glycine and $\left[{ }^{3} \mathrm{H}\right]$ strychnine binding sites in the rat brain. Eur. J. Pharmacol.126:303-307; 1986.

16. Burke, W. J.; Chung, H. D.; Huang, J. S.; Huang, S. S.; Haring, J. H.; Strong, R.; Marshall, G. L.; Joh, T. H. Evidence for retrograde degeneration of epinepherine neurons in Alzheimer's disease. Ann. Neurol. 24:532-536; 1988.

17. Cha, J-H.; Greenamyre, J. T.; Nielsen, E. O.; Penney, J. B.; Young, A. B. Properties of quisqualate-sensitive $\mathrm{L}-\left[{ }^{3} \mathrm{H}\right] \mathrm{glutamate}$ binding sites in rat brain as determined by quantitative autoradiography. $\mathrm{J}$. Neurochem. 51:469-478; 1988.

18. Choi, D. W. Ionic dependence of glutamate neurotoxicity. J. Neurosci. 7:369-379; 1987.

19. Collingridge, G. L.; Bliss, T. V. P. NMDA receptors-their role in long-term potentiation. Trends Neurosci. 10:288-293; 1987.

20. Collingridge, G. L.; Kehl, S. J.; McLennan, H. Excitatory amino acids in synaptic transmission in the Schaffer collateral-commissural pathway of the rat hippocampus. J. Physiol. (Lond.) 334:33-46; 1983.

21. Conti, F.; Fabri, M.; Manzoni. T. Glutamate-positive corticocortical neurons in the somatic sensory areas I and II of cats. J. Neurosci. $8: 2948-2960 ; 1988$.

22. Cotman, C. W.; Iversen, L. L. Excitatory amino acids - focus on NMDA receptors. Trends Neurosci. 10:263-265; 1987.

23. Cotman, C. W.; Monaghan, D. T.; Ottersen, O. P.; Storm-Mathisen, $\mathrm{J}$. Anatomical organization of excitatory amino acid receptors and their pathways. Trends Neurosci. 7:273-280; 1987.

24. Cowburn. R.; Hardy, J.; Roberts, P.; Briggs, R. Presynaptic and postsynaptic glutamatergic function in Alzheimer's disease. Neurosci. Lett. 86:109-113; 1988

25. Cowburn, R.; Hardy, J.; Roberts, P.; Briggs, R. Regional distribution of pre- and postsynaptic glutamatergic function in Alzheimer's disease. Brain Res. 452:403-407; 1988.

26. Coyle, J. T.; Price, D. L.; DeLong, M. R. Alzheimer's disease: A disorder of cortical cholinergic innervation. Science 219:1184-1190; 1983.

27. Coyle, J. T.; Schwarcz, R. Lesion of striatal neurons with kainic acid provides a model for Huntington's chorea. Nature 263:244-246; 1976.

28. Cross, A. J.; Slater, P.; Candy, J. M.; Perry, E. K.; Perry, R. H. Glutamate deficits in Alzheimer's disease. J. Neurol. Neurosurg. Psychiatry 50:357-358; 1987

29. Crunelli, V.; Forda, S.; Kelly, J. S. Blockade of amino acid-induced depolarizations and inhibition of excitatory postsynaptic potentials in rat dentate gyrus. J. Physiol. (Lond.) 341:627-640; 1983.

30. Danbolt, N. C.; Storm-Mathisen, J. Na ${ }^{+}$-dependent "binding" of 
D-aspartate in brain membranes is largely due to uptake into membrane-bounded saccules. J. Neurochem. 47:819-824; 1986.

31. Davies, P.; Maloney, A. J. Selective loss of central cholinergic neurones in Alzheimer's disease. Lancet 2:1430; 1976

32. De Boni, U.; Crapper-McLachlan, D. R. Controlled induction of paired helical filaments of the Alzheimer's type in cultured human neurons, by glutamate and aspartate. J. Neurol. Sci. 68:105-118; 1985.

33. Deutsch, S. I.; Morihisa, J. M. Glutamatergic abnormalities in Alzheimer's disease and a rationale for clinical trials with Lglutamate. Clin. Neuropharmacol, 11:18-35; 1988.

34. Dhindsa, K. S. Cytochemical studies demonstrating the effect of monosodium glutamate on RNA concentration in neurons in mice. Acta Anatomica. (Lond.) 116:201-205; 1983.

35. Ellison, D. W.; Beal, M. F.; Mazurek, M. F.: Bird, E. D.; Martin, J. B. A postmortem study of amino acid neurotransmitters in Alzheimer's disease. Ann. Neurol. 20:616-621; 1986.

36. Engelsen, B. Neurotransmitter glutamate: its clinical importance. Acta Neurol. Scand. 74:337-355; 1986.

37. Esiri, M. M.; Pearson, R. C. A.; Powell, T. P. S. The cortex of the primary auditory area in Alzheimer's disease. Brain Res. 366: 385-387; 1986.

38. Fagg, G. E.; Foster, A. C. Amino acid neurotransmitters and their pathways in the mammalian central nervous system. Neuroscience 9:701-719; 1983.

39. Fonnum, F. Glutamate: a neurotransmitter in mammalian brain. J. Neurochem. 42:1-11; 1984

40. Foster, A. C.; Gill, R.; Woodruff, G. N.; Iversen, L. L. Noncompetitive NMDA receptor antagonists and ischaemia-induced neuronal degeneration. In: Cavalheiro, E. A.; Lehmann, J.; Turski, L., eds. Frontiers in excitatory amino acid research. New York: Alan Liss; 1988:707-714

41. Ganong, A. H.; Cotman, C. W. Kynurenic acid and quinolinic acid act at $\mathrm{N}$-methyl-D-aspartate receptors in the rat hippocampus. J. Pharmacol. Exp. Ther. 236:293-299; 1985

42. Geddes, J. W.; Chang-Chui, H.; Cooper, S. M.; Lott, I. T.; Cotman, C. W. Density and distribution of NMDA receptors in the human hippocampus in Alzheimer's disease. Brain Res. 399:156-161; 1986.

43. Geddes, J. W.; Monaghan, D. T.; Cotman, C. W.; Lott, I. T.; Kim, R. C.; Chui, H. C. Plasticity of hippocampal circuitry in Alzheimer's disease. Science 230:1179-1181; 1985.

44. Greenamyre, J. T. The role of glutamate in neurotransmission and in neurologic disease. Arch. Neurol. 43:1058-1063; 1986.

45. Greenamyre, J. T.; Olsen, J. M. M.; Penney, J. B.; Young, A. B. Autoradiographic characterization of N-methyl-D-aspartate-, quisqualate- and kainate-sensitive glutamate binding sites. J. Pharmacol. Exp. Ther. 233:254-263; 1985.

46. Greenamyre, J. T.; Penney, J. B.; D'Amato, C. J.; Young, A. B. Dementia of the Alzheimer's type: changes in hippocampal L$\left[{ }^{3} \mathrm{H}\right]$ glutamate binding. J. Neurochem. 48:543-551; 1987.

47. Greenamyre, J. T.; Penney, J. B.; Young, A. B.; D'Amato, C. J.; Hicks. S. P.; Shoulson, I. Alterations in L-glutamate binding in Alzheimer's and Huntington's diseases. Science 227:1496-1499; 1985

48. Greenamyre, J. T.; Higgins, D. S.; Young, A. B. Sodium-dependent D-aspartate "binding" is not a measure of presynaptic neuronal uptake sites in an autoradiographic assay. Brain Res.: in press.

49. Hardy, J.; Cowburn, R.; Barton, A.; Reynolds, G.; Lofdahl, E.; O'Carroll, A.; Wester, P.; Winblad, B. Region-specific loss of glutamate innervation in Alzheimer's disease. Neurosci. Lett, 73: $77-80 ; 1987$

50. Harris, E. K.; Ganong, A. H. Cotman, C. W. Long term potentiation in the hippocampus involves activation of N-methyl-D-aspartate receptors. Brain Res. 323:132-137; 1984.

51. Honore, T.; Drejer, J.; Nielsen, M. Calcium discriminates two $\left[{ }^{3} \mathbf{H}\right]$ kainate binding sites with different molecular target sizes in rat cortex. Neurosci. Lett. 65:47-52; 1986.

52. Honore, T.; Lauridsen, J.; Krogsgaard-Larsen, P. The binding of $\left[{ }^{3}\right.$ H]AMPA a structural analogue of glutamic acid to rat brain membranes. J. Neurochem. 38:173-178; 1982.

53. Hyman, B. T.; Van Hoesen, G.; Damasio, A. Alzheimer's disease: glutamate depletion in the hippocampal perforant pathway zone.
Ann. Neurol. 22:37-38; 1987

54. Hyman, B. T.; Van Hoesen, G. W.; Damasio, A. R.; Barnes, C. L. Alzheimer's disease: Cell-specific pathology isolates the hippocampal formation. Science 225:1168-1170; 1984

55. Hyman, B. T.; Van Hoesen, G. W.; Kromer, L. J.; Damasio, A. R. Perforant pathway changes and the memory impairment of Alzheimer's disease. Ann. Neurol. 20:472-481; 1986

56. Ihara, Y. Massive somatodendritic sprouting of cortical neurons in Alzheimer's disease. Brain Res. 459:138-144; 1988.

57. Iqbal, K.; Grundke-Iqbal, I.; Zaidi, T.; Merz, P. A.; Wen, G. Y. Shaikh, S. S.; Wisniewski, H. M.; Alafuzoff, I.; Winblad, B. Defective brain microtubule assembly in Alzheimer's disease. Lancet $2: 421-426 ; 1986$.

58. Johnson, J. W.; Ascher, P. Glycine potentiates the NMDA response in cultured mouse brain neurons. Nature 325:529-531; 1988

59. Kemp, J. A.; Foster, A. C.; Wong, E. H. F. Non-competitive antagonists of excitatory amino acid receptors. Trends Neurosci. 10:294-298; 1987.

60. Khachaturian, Z. S. Diagnosis of Alzheimer's disease. Arch. Neurol. 42:1097-1105; 1985 .

61. Kish, S. J.; Munir, E- A.; Schut, L.; Leach, L.; Oscar-Berman, M.; Freedman, M. Cognitive deficits in olivopontocerebellar atrophy: Implications for the cholinergic hypothesis of Alzheimer's dementia. Ann. Neurol. 24:200-206; 1988

62. Kleckner. N. W.; Dingledine, R. Requirement for glycine in activation of NMDA-receptors expressed in Xenopus oocytes. Science 241:835-837; 1988

63. Kleinschmidt, A.; Bear, M. F.; Singer, W. Blockade of NMDA receptors disrupts experience-dependent plasticity of kitten striate cortex. Science 238:355-358; 1986.

64. Kowall, N. W.; Kosik, K. S.; Beal, M. F. Glutamatergic neurons in the hippocampus are morphologically abnormal and develop neurofibrillary tangles in Alzheimer's disease. Soc. Neurosci. Abstr $13: 215-215 ; 1987$

65. Lewis, P. N.; Lukiw, W. J.; DeBoni, U.; Crapper-McLachlan, D $R$. Changes in chromatin structure associated with Alzheimer's disease. J. Neurochem. 37:1193-1202; 1981.

66. Liston, D.; Russo, L.; Mena, E. E.; Williams, I. Tetrahydroaminoacridine is concentrated in brain following intraperitoneal admin istration. Soc. Neurosci. Abstr. 14:1224; 1988.

67. Lodge, D.; Anis, N. A. Effects of phencyclidine on excitatory amino acid activation of spinal interneurones in the cat: Eur. J. Pharmacol. 77:203-204; 1982

68. McDonald, J. W.; Penney, J. B.; Johnston, M. V.; Young, A. B. Quantitative autoradiography of $\left[{ }^{3} \mathrm{H}\right]$ glycine binding to the glycine receptor associated with the NMDA receptor operated channel. Soc Neurosci. Abstr. 14:484; 1988.

69. McGeer, E. G.; McGeer, P. L. Duplication of biochemical changes of Huntington's chorea by intrastriatal injections of glutamic and kainic acids. Nature 263:517-519; 1976.

70. Mann, D. M. A.; Yates, P. O. Serotonin nerve cells in Alzheimer's disease. J. Neurol. Neurosurg. Psychiatry 43:113-119;1982.

71. Mann, D. M. A.; Yates, P. O.; Marcyniuk, B. A comparison of nerve cell loss in cortical and subcortical structures in Alzheimer's disease. J. Neurol. Neurosurg. Psychiatry 49:310-312; 1986.

72. Maragos, W. F.; Chu, D. C. M.; Young, A. B.; D'Amato, C. J. Penney, J. B. Loss of hippocampal $\left[{ }^{3} \mathrm{H}\right] \mathrm{TCP}$ binding in Alzheimer's disease. Neurosci. Lett. 74:371-376; 1987.

73. Maragos, W. F.; Debowey, D. L.; Reiner, A.; Rustioni, A.; Penney, J. B.; Young, A. B. Co-localization of Congo Red-stained neurofibrillary tangles in glutamate immunoreactive neurons in hippocampus. Soc. Neurosci. Abstr. 12:442-442; 1986.

74. Maragos, W. F.; Penney, J. B.; Young, A. B. Anatomic correlation of NMDA and ${ }^{3} \mathrm{H}$-TCP-labeled receptors in rat brain. J. Neurosci. $8: 493-501 ; 1988$

75. Mattson, M. P. Neurotransmitters in the regulation of neuronal cytoarchitecture. Brain Res. Rev. 13:179-212;1988.

76. Mattson, M. P.; Dou, P.; Kater, S. B. Outgrowth-regulating actions of glutamate in isolated hippocampal pyramidal neurons: J. Neturosci. $8: 2087-2100 ; 1988$.

77. Mattson, M. P.; Kater, S. B. Development and selective neurodegeneration in cell cultures from different hippocampal regions. Brain Res. . in press: 1989. 
78. Mayer, M. L.; Westbrook, G. L. The physiology of excitatory amino acids in the vertebrate central nervous system. Prog. Neurobiol. 28:197-276; 1987.

79. Mayer, M. L.; Westbrook, G. L.; Guthrie, P. B. Voltage-dependent block by $\mathrm{Mg}^{+2}$ of NMDA responses in spinal cord neurons. Nature 309:261-263; 1984

80. Mehraein, P.; Yamada, M.; Tarnowska-Dziduszko, E. Quantitative study on dendrites and dendritic spines in Alzheimer's disease and senile dementia. Adv. Neurol. 12:453-458; 1975.

81. Monaghan, D. T.; Cotman, C. W. The distribution of $\left[{ }^{3} \mathrm{H}\right]$ kainic acid binding sites in rat CNS as determined by autoradiography. Brain Res. 252:91-100; 1982

82. Monaghan, D. T.; Geddes, J. W.; Yao, D.; Chung, C.; Cotman, C. W. $\left[{ }^{3} \mathrm{H}\right] \mathrm{TCP}$ binding sites in Alzheimer's disease. Neurosci. Lett. 73:197-200; 1987

83. Monaghan, D. T.; Holets, V. R.; Toy, D. W.; Cotman, C. W. Anatomical distributions of four pharmacologically distinct ${ }^{3} \mathrm{H}-$ L-glutamate binding sites. Nature 306:176-179; 1983.

84. Monaghan, D. T.; Olverman, H. J.; Nguyen, L.; Watkins, J. C.; Cotman, C. W. Two classes of N-methyl-D-aspartate recognition sites: Differential distribution and differential regulation by glycine. Proc. Natl. Acad, Sci. USA 85:9836-9840; 1988.

85. Monaghan, D. T.; Yao, D.; Cotman, C. W. L- $\left[{ }^{3} \mathrm{H}\right]$ glutamate binds to kainate-, NMDA- and AMPA-sensitive binding sites: an autoradiographic analysis. Brain Res. 340:378-383; 1985.

86. Monaghan, D. T.; Yao, D.; Cotman, W. Distribution of [ $\left.{ }^{3} \mathrm{H}\right] \mathrm{AMPA}$ binding sites in rat brain as determined by quantitative autoradiography. Brain Res. 324:160-164; 1984

87. Morris, R. G. M.; Anderson, E.; Lynch, G. S.; Baudry, M. Selective impairment of learning and blockade of longterm potentiation by an N-methyl-D-aspartate antagonist, APS. Nature 319: $774-776 ; 1986$.

88. Naito, S.; Ueda, T. Adenosine triphosphate-dependent uptake of glutamate into protein I-associated vesicles. J. Biol. Chem. 258: 696-699; 1983 .

89. Neary, D.; Snowden, J. S.; Mann, D. M. A.; Bowen, D. M.; Sims, N. R.; Northen, B.; Yates, P. O.; Davison, A. N. Alzheimer's disease: a correlative study. J. Neurol. Neurosurg. Psychiatry 49: 229-237: 1986

90. Nicoletti, F.; Meek, J. L.; Iadarola, M. J.; Chuang, D. M.; Roth. B. L. Costa, E. Coupling of inositol phospholipid metabolism with excitatory amino acid recognition sites in rat hippocampus. J. Neurochem. 46:40-46; 1985.

91. Nielsen. E. O.; Cha, J. J.; Honore, T.; Penney, J. B.; Young, A. B. Thiocyanate stabilizes AMPA binding to the quisqualate receptor. Eur. J. Pharmacol. 157:197-203; 1988.

92. Novelli, A.; Reilly, J. A.; Lysko, P. G.; Henneberry, R. C. Glutamate becomes neurotoxic via the N-methyl-D-aspartate receptor when intracellular energy levels are reduced. Brain Res. 451: 205-212; 1988.

93. Nowak, L.; Bregestovski, P.; Ascher, P.; Herbert, A.; Prochiantz, A. Magnesium gates glutamate-activated channels in mouse central neurones. Nature 307:462-466; 1984.

94. Olney, J. W.; Ho, O. C.; Rhee, V. Cytotoxic effects of acidic and sulphur containing amino acids on the infant mouse central nervous system. Exp. Brain Res. 14:61-76; 1971 .

95. Ottersen, O. P.; Bramham. C. R. Quantitative electron microscopic immunocytochemistry of excitatory amino acids. In: Cavalheiro, E. A.; Lehmann, J.; Turski, L., eds. Frontiers in excitatory amino acid research, New York: Alan R. Liss, Inc.; 1988:93-100.

96. Palmer, A. M.; Procter, A. W.; Stratmann, G. C.; Bowen, D. M. Excitatory amino acid-releasing and cholinergic neurones in Alzheimer's disease. Neurosci. Lett. 66:199-204; 1986.

97. Pardridge, W. M. Regulation of amino acid availability to brain: selective control mechanisms for glutamate. In: Filer, J.; Garrattini, S.; Kare, M. R.; Reynolds, W. A.; Wurtman, R. J., eds. Glutamic acid: Advances in biochemistry and physiology. New York: Raven Press; 1979:125-127.

98. Pearce, B. D.; Potter, L. T. Effects of tetrahydroaminoacridine on M1 and M2 muscarine receptors. Neurosci. Lett. 88:281-285; 1988.

99. Pearson, R. C. A.; Esiri, M. M.; Hiorns, R. W.; Wilcock, G. K.; Powell, T. P. S. Anatomical correlates of the distribution of the pathological changes in the neocortex in Alzheimer's disease. Proc.
Natl. Acad. Sci. USA 82:4531-4534; 1985.

100. Pearson, R. C. A.; Gatter, K. C.: Powell, T. P. S. Retrograde cell degeneration in the basal nucleus in monkey and man. Brain Res. 261:321-326; 1983 .

101. Pearson, R. C. A.; Sofroniew, M. V.; Cuello, A. C.; Powell, T. P. S.; Eckenstein, F.; Esiri, M. M.; Wilcock, K. Persistence of cholinergic neurons in the basal nucleus in a brain with senile dementia of the Alzheimer's type demonstrated by immunohistochemical staining for choline acetyltransferase. Brain Res. 289: 375-379; 1983.

102. Perry, E. K.; Atack, J. R.; Perry, R. H.; Hardy, J. A.; Dodd, P. R.; Edwardson, J. A.; Blessed, G.; Tomlinson, B. E.; Fairbairn, A. F. Intralaminar neurochemical distribution in human midtemporal cortex: comparison between Alzheimer's disease and the normal. J. Neurochem. 42:1402-1410; 1984.

103. Perry, R. H.; Candy, J. M.; Perry, E. K.; Irving, D.; Blessed, G.; Fairbairn, A. F.; Tomlinson, B. E. Extensive loss of choline acetyltransferase activity is not reflected by neuronal loss in the nucleus of Meynert in Alzheimer's disease. Neurosci. Lett. 33: $311-315 ; 1982$.

104. Perry, T. L.; Yong, V. W.; Bergeron, C.; Hansen, S.; Jones, K. Amino acids, glutathione, and glutathione transferase activity in the brains of patients with Alzheimer's disease. Ann. Neurol. 21: 331-336; 1987.

105. Potashner, S. J. The spontaneous and electrically-evoked release from slices of guinea pig cerebral cortex of endogenous amino acids labeled via metabolism of D-[U- $\left.{ }^{14} \mathrm{C}\right]$ glucose. J. Neurochem. 31: $177-186 ; 1978$.

106. Price, D. L.; Whitehouse, P. J.; Struble, R. G.; Clark, A. W.; Coyle, J. T.; DeLong, M. R.: Hedreen. J. C. Basal forebrain cholinergic systems in Alzheimer's disease and related dementias. Neurosci. Comment. 1:84-92; 1982.

107. Probst, A.; Basler, V.; Bron, B.; Uirich. J. Neuritic plaques in senile dementia of Alzheimer's type: A Golgi analysis in the hippocampal region. Brain Res. 268:249-254; 1983.

108. Procter, A. W.; Palmer, A. M.; Francis, P. T.: Lowe, S. L.; Neary, D.: Murphy, E.; Doshi, R.; Bowen, D. M. Evidence of glutamatergic denervation and possible abnormal metabolism in Alzheimer's disease. J. Neurochem. 50:790-802: 1988.

109. Quirion, R.; Chicheportiche, R.: Contrera. P. C.; Johnson, K. M.; Lodge, D.; Tam, S. W.; Woods, J. H.; Zukin, S. R. Classification of nomenclature of phencyclidine and sigma receptor sites. In: Domino. E. F.; Kamenka, J-M., eds. Sigma and phencyclidine-like compounds as molecular probes in biology. Ann Arbor: NPP Books; 1988:601-606

110. Rauschecker, J. P.; Hahn, S. Ketamine-xylazine anaesthesia blocks consolidation of ocular dominance changes in kitten visual cortex. Nature 326:183-185; 1987

111. Represa, A.; Duyckaerts, C.: Tremblay, E.; Hauw, J. J.; Ben-Ari, $Y$. Is senile dementia of the Alzheimer type associated with hippocampal plasticity? Brain Res. 452:403-407; 1988.

112. Reynolds, I. J.; Murphy, S. N.; Miller, R. J. ${ }^{3} \mathrm{H}$-Labeled MK-801 binding to the excitatory amino acid receptor complex from rat brain is enhanced by glycine. Proc. Natl. Acad. Sci. USA 84:7744--7748; 1987.

113. Rogers, J.; Morrison, J. H. Quantitative morphology and regional and laminar distributions of senile plaques in Alzheimer's disease. J. Neurosci. 5:2801-2808: 1985 .

114. Rothman, S. M.; Olney, J. W. Glutamate and the pathophysiology of hypoxic-ischemic brain damage. Ann. Neurol. 19:105-111: 1986.

115. Rothman, S. M.; Olney, J. W. Excitotoxicity and the NMDA receptor. Trends Neurosci. 7:299-302; 1987.

116. Sasaki, H.; Muramoto, O.; Kanazawa, I.; Arai, H.; Kosaka, K.; Iizuka, R. Regional distribution of amino acid transmitters in postmortem brains of presenile and senile dementia of Alzheimer type. Ann. Neurol. 19:263-269: 1986.

117. Schwarcz, R. Effects of tissue storage and freezing on brain glutamate uptake. Life Sci. 28:1147-1154; 1980

118. Shankar, S. K.; Yanagihara, R.; Garruto, R. M.; Grundke-Iqbal, I.; Koski, K. S.; Gajdusek, D. C. Immunocytochemical characterization of neurofibrillary tangles in amyotrophic lateral sclerosis and parkinsonism-dementia of Guam. Ann. Neurol. 25:146-151; 1989.

119. Shaw, F. H.; Bentley, G. Some aspects of the pharmacology of 
morphine with special reference to its antagonism by 5 -aminoacridine (THA) and other chemically related compounds. Med. J. Aust. $2: 868-874 ; 1949$.

120. Silverstein, F. S.; Buchanan, K.; Johnston, M. V. Perinatal hypoxiaischemia disrupts striatal high-affinity $\left[{ }^{3} \mathrm{H}\right]$ glutamate uptake into synaptosomes. J. Neurochem. 47:1614-1619; 1986.

121. Simon, J. R.; Contrera, J. F.; Kuhar, M. J. Binding of $\left[{ }^{3} \mathrm{H}\right]$ kainic acid, an analogue of L-glutamate, to brain membranes. J. Neurochem. 26:141-147; 1976.

122. Simon, R. P.; Swan, J. H.; Griffiths, T.; Meldrum, B. S. Blockade of $\mathrm{N}$-methyl-D-aspartate receptors may protect against ischemic damage in the brain. Science $226: 850-852 ; 1984$.

123. Simpson, M. D. C.; Royston, M. C.; Deakin, J. F. W.; Cross, A. J.; Mann, D. M. A.; Slater, P. Regional changes in $\left[{ }^{3} \mathrm{H}\right] \mathrm{D}$-aspartate and $\left[{ }^{3} \mathrm{H}\right] \mathrm{TCP}$ binding sites in Alzheimer's disease brains. Brain Res. 462:76-82; 1988.

124. Sircar, R.; Zukin, S. R. Quantitative localization of $\left[{ }^{3} \mathrm{H}\right] \mathrm{TCP}$ binding in rat brain by light microscopy autoradiography. Brain Res. 344:142-145; 1985.

125. Sladeczak, F.; Pin, J. P.; Recasens, M.; Bockaert, J.; Weiss, S. Glutamate stimulates inositol phosphate formation in striatal neurons. Nature 317:717-720; 1985.

126. Sloviter, R. S. "Epileptic" brain damage in rats induced by sustained electrical stimulation of the perforant path. I. Acute electrophysiological and light microscopic studies. Brain Res. Bull. $10: 675-697 ; 1983$.

127. Smith, C. C. T.; Bowen, D. M.; Francis, P. T.; Snowden, J. S.; Neary, D. Putative amino acid transmitters in lumbar cerebrospinal fluid of patients with histologically verified Alzheimer's dementia. J. Neurol. Neurosurg. Psychiatry 48:469-471; 1985.

128. Smith, C. C. T.; Bowen, D. M.; Sims, N. R.; Neary, D.; Davison, A. N. Amino acid release from biopsy samples of temporal neocortex from patients with Alzheimer's disease. Brain Res. 264:138-141; 1983.

129. Smith, S. Dynamic changes of synaptic structure under normal and experimental conditions. Soc. Neurosci. Abstr. 13:1001; 1987

130. Snell, L. D.; Morter, R. S.; Johnson, K. M. Structural requirements for activation of the glycine receptor that modulates the N-methylD-aspartate operated ion channel. Eur. J. Pharmacol. 156:105-110; 1988.

131. Sofroniew, M. V.; Isacson, O.; Bjorklund, A. Cortical grafts prevent atrophy of cholinergic basal nucleus neurons induced by excitotoxic cortical damage. Brain Res. 378:409-415; 1986.

132. Spencer, P. S.; Ludolph, A.; Dwived, M. P.; Roy, D. N.; Hugon, J.; Schamburg, H. H. Lathyrism: evidence for role of the neuroexcitatory amino acid BOAA. Lancet $2: 1066-1067 ; 1986$.

133. Spencer, P. S.; Nunn, P. B.; Hugon, J.; Ludolph, A. C.; Ross, S. M.: Roy, D. N.; Robertson, R. C. Guam amyotrophic lateral sclerosis-parkinsonism-dementia linked to a plant excitant neurytoxin. Science 237:517-522; 1987.

134. Storm-Mathisen, J.; Leknes, A. K.; Bore, A. T.; Vaaland, I. L.; Edminson, P.; Haug. F. M. S.; Ottersen, O. P. First visualization of glutamate and GABA in neurones by immunocytochemistry. Nature 301:517-520; 1988 .

135. Summers, W. K.; Majorski, L. V.; Marsh, G. H.; Tachiki, K.; Kling, A. Oral tetrahydroaminoacridine in long-term treatment of senile dementia, Alzheimer type. N. Engl. J. Med. 315:1241-1245: 1986.

136. Terry, R. D.; Katzman, R. Senile dementia of the Alzheimer type. Ann. Neurol. 14:497-506; 1986.

137. Terry, R. D.; Peck, A.; Deteresa, R.; Schechter, R.; Horoupian, D. $\mathrm{S}$. Some morphometric aspects of the brain in senile dementia of the Alzheimer type. Ann. Neurol. 10:1168-1170; 1981.

138. Thomson, A. M.; West, D. C.; Lodge, D. An N-methylaspartate receptor-mediated synapse in rat cerebral cortex: a site of action of ketamine. Nature 313:479-482; 1985

139. Toth, E.; Lajtha, A. Elevation of cerebral levels of nonessential amino acids in vivo by administration of large doses. Neurochem. Res. 6:1309-1317; 1981.

140. Unnerstall, J. R.; Wamsley, J. K. Autoradiographic localization of high affinity $\left[{ }^{3} \mathrm{H}\right]$ kainic acid binding sites in the rat forebrain. Eur J. Pharmacol. 86:361-371; 1983.

141. Vignon, J.; Vincent, J.; Bidard, J.; Kamenka, J.; Geneste, P.; Monier, S.; Lazdunski, M. Biochemical properties of the brain phencyclidine receptor. Eur. J. Pharmacol. 81:531-542; 1982.

142. Watkins, J. C.; Evans, R. H. Excitatory amino acid transmitters. Annu. Rev. Pharmacol. Toxicol, 21:165-204; 1981.

143. Whitehouse, P. J. The concept of subcortical and cortical dementia: Another look. Ann. Neurol. 19:1-6; 1986.

144. Wieloch, T. Endogenous excitotoxins as possible mediators of ischemic and hypoglycemic brain damage. Epilepsia 26:501; 1985.

145. Wieloch, T. Hypoglycemia-induced neuronal damage prevented by an N-methyl-D-aspartate antagonist. Science $230: 681-683 ; 1985$

146. Wisniewski, H. M.; Kozlowski, P. B. Evidence for blood-brain barrier changes in senile dementia of the Alzheimer type (SDAT). Ann. NY Acad. Sci. 396:119-129; 1982.

147. Young, A. B.; Greenamyre, 1. T.; Hollingsworth, Z.; Albin, R.; D'Amato, C, Shoulson, I.: Penney, J. B. NMDA receptor losses in putamen from patients with Huntington's disease. Science 241 $981-983 ; 1988$.

148. Zhu, S. G.; McGreer, E. G.; Singh, E. A.; McGreer, P. L. Tetrahydroaminoacridine potentiates neurotoxicity of quinolinic acid in rat striatum. Neurosci. Lett. 95:252-256; 1988.

149. Zukin, S. R.; Zukin, R. S. Specific $\left[{ }^{3} \mathrm{H}\right]$ phencyclidine binding in rat central nervous system. Proc. Natl. Acad. Sci. USA 76:5372-5376 1979 . 